\title{
LA GEOGRAFÍA HOMÉRICA
}

\author{
CARLA BOCCHETTI \\ Departamento de Literatura \\ Universidad del Rosario (Colômbia)
}

\begin{abstract}
RESUMO: Este artigo estuda o Catálogo das Naus na Ilíada como um mapa oral da Grécia. Defende-se aqui que o catálogo serve como documento cultural que fornece idéias de pertencimento e unidade aos gregos, e pode ser visto como exemplo antigo de pan-helenismo.
\end{abstract}

PALAVRAS-CHAVE: Homero; Catálogo das Naus; geografia antiga; literatura de viagem; mapas orais.

\section{Introducción}

La Ilíada y la Odisea poseen información geográfica de características diversas. Desde la antigüedad se consideró que la geografía que aparece en la Ilíada, especialmente el catálogo de las naves (Il. 2. 495-759), representa una geografía real, mientras que la geografía de la Odisea se ha considerado comúnmente como fantástica. La geografía del Catálogo de las naves ha sido estudiada principalmente por arqueólogos quienes han excavado la mayoría de los lugares allí mencionados con el interés de establecer el período histórico al que pertenece el catálogo. La Odisea también ha inspirado a muchos a realizar viajes en busca de la ruta de Odiseo, pero estos viajes se pueden enmarcar dentro de un contexto de utopía, ya que las aventuras de Odiseo están situadas en un mundo de ficción.

Este artículo propone demostrar que el Catalogo de las naves de la Ilíada, el cual menciona todos los guerreros que participaron en la guerra de Troya y sus lugares de origen, puede ser considerado como el primer mapa de toda Grecia del que tenemos noticia ${ }^{1}$. El catalogo contiene una descripción de Grecia continental:

1 El tema de la geografía homérica y su interpretación como geografía cultural está tratado en extensión en el artículo "Cultural Geography in Homer", Carla Bocchetti 
del Peloponeso, de Etolia, de Tesalia, de Atica y Beocia, y de las costas del Asia menor. No menciona las islas con excepción de Creta y de las islas de Cefolonia.

Miremos un ejemplo del catálogo:

Los que habitaban el Argos Pelásgico, los que administraban Alo, Alope y Trequine, los que poseían Ftía y Hélade, de bellas mujeres: se llamaban mirmidones, helenes y aqueos.

De sus cincuenta naves era jefe Aquiles

(Il. 2. 681-685; trad. Crespo).

La condición de Homero como geógrafo en la antiguedad es vista desde dos opiniones distintas. Una, lo considera como el padre de la geografía, y esta opinión es expresada por Estrabón quien lo usa como modelo para escribir su propia obra geográfica. La otra, lo considera exponente de un parámetro dudoso de hacer geografía, y es criticado severamente por Heródoto y Eratóstenes.

Una de las ideas que propongo demostrar, ligada al argumento de si Homero era un buen geógrafo o no, es que toda la geografía antigua tiene que estudiarse unida al tema de la literatura de viajes. Es por ésto, que aunque la geografía de la Odisea y de la Ilíada sean de naturaleza distinta, ambas pueden ser estudiadas bajo la estructura del Periplo.

El viaje que narra la Odisea describe lugares imaginarios que reflejan el contacto de los griegos con otras culturas y los lugares míticos existentes en la imaginación geográfica de ese entonces, como la isla de los bienaventurados y la descripción paradisíaca descrita en la isla de los cíclopes. Algunos autores consideran que son experiencias del período de protocolonización griega, cuando las ciudades estados (polis) exploraron distintos lugares para establecer colonias y se cree que es la descripción de lugares del sur de Italia, Sicilia, el estrecho de Messina y Corfú (Malkin, 1998, p. 1-10). Sin embargo, algunos autores consideran que la geografía de la Odisea es imaginaria y no puede ser plasmada en un mapa real (p. ej., Páramo, 1991).

El Periplo realizado por Odiseo representa una muestra de la influencia del tema del viaje en la literatura. A pesar de que no pretende ser la descripción de un

(2003) ERAS Journal: School of Historical Studies, Online Journal, 5th Edition, Australia. 
viaje real, éste puede ser de gran ayuda para entender la forma como el poeta antiguo construye la organización del espacio, y cómo esta organización permea la descripción de Grecia en el catálogo de las naves. Es así que la geografía tal y como está representada en la Odisea, en su calidad de fantástica, sirve de ayuda para entender la geografía real e histórica que aparece plasmada en el Catálogo de las naves: ambas forman parte de una concepción del espacio concebido en la misma forma como están construidos los relatos de viajes.

Como está demostrado en la Odisea que la geografía va unida a la idea de viaje, es mi propósito demostrar que en el caso del Catálogo de las Naves de la Ilíada, también la organización del espacio está basado en relatos de viajes. Antes de presentar los argumentos para demostrar esta idea miremos los problemas que comúnmente se le atribuyen al catálogo sobre su historicidad, datación y calidad literaria.

\section{Los problemas del catálogo}

El problema de la historicidad del catálogo y la perspectiva arqueológica desde la cual ha sido estudiado ha impedido una aproximación desde una perspectiva literaria. Por ejemplo, arqueólogos como Allen (1921) y Hope Simpson-Lazenby (1970) consideran el catálogo como un documento histórico y tratan de establecer el período al cual pertenece su descripción geográfica. Los problemas que surgen a partir de una perspectiva histórica crean opiniones ambivalentes sobre éste. El solo nombre "catálogo de las naves" lleva a los estudiantes a pensar en una lista larga y aburrida de nombres que impide el desarrollo de la historia y que no posee una función dramática. Por ejemplo, Bowra (1930, p. 71-72) reconoce que el catálogo ayuda a mostrar el tamaño de la armada que fue a Troya y es útil para los antecedentes de la guerra, los guerreros involucrados en ésta y los eventos que siguen, pero no sirve a estos propósitos de forma ideal. Crossett (1968, p. 241) se interesa por el catálogo pero evade su contenido geográfico y se centra en los símiles que anteceden la información geográfica. Otros autores han trabajado extensamente en el catálogo. Por ejemplo, Page (1959, p. 120-129) combina la evidencia arqueológica con asuntos literarios y presenta un argumento extenso sobre el catálogo y sus problemas, sus conclusiones principales son: la geografía del catálogo es de origen micénico, el catálogo fue compuesto por separado de la Ilíada y adaptado posteriormente al contexto de la guerra de Troya. Kirk (1985, p. 168263) presenta un trabajo extenso sobre el catálogo, y considera que de alguna manera el catálogo refleja la geografía de Grecia de cualquier período ya que los 
lugares que menciona fueron ocupados a lo largo de toda la antigüedad. Estos dos argumentos: que la geografía del catálogo refleja la Grecia micénica o que representa una mezcla de la geografía de diferentes períodos históricos son las dos directrices principales en que el catálogo ha sido estudiado. Sin embargo, yo pienso que el estudiante de Homero no puede seguir haciéndose la pregunta tradicional de la fecha de composición del catálogo y del período histórico que éste refleja. Es necesario cambiar el tipo de preguntas que usualmente se formulan y empezar a considerarlo como un mapa sobre el cual se construye la identidad heroica del pueblo griego.

Sin embargo, el trabajo más reciente sobre el catálogo Homers Katalog der Schiffe de Visser (1997, p. 747) sigue la misma perspectiva tradicional. Este concluye que el catálogo fue compuesto en el período Geométrico tardío (700 aC), y que Homero combina el conocimiento geográfico de este período con el conocimiento geográfico acuñado por el material mítico a través de la tradición épica. Con relación a de dónde obtiene Homero su conocimiento geográfico, Visser piensa que la geografía del catálogo no refleja la época Micénica ni la del período Oscuro (siglos X-IX aC), considera que es el producto de la improvisación de la poesía oral y que no necesariamente pertenece a un periodo anterior. Por otro lado, considera que el catálogo no contiene innovaciones poéticas ya que el poeta conoce las diferentes localidades a través de su conocimiento de los mitos y es el mito de Troya la guía para seleccionar los nombres geográficos. Sin embargo, como veremos más adelante, Homero enfatiza en el catálogo las localidades no relacionadas al mito de Troya como es el caso de Beocia y Corinto.

Giovannini (1969, p. 51-52) es otro autor que trabaja el problema de la datación del catálogo. Argumenta que Homero contiene su información geográfica de listas de theorodokoi (listas de ciudades que enviaban regalos al santuario de Delfos) similares a aquellas encontradas con inscripciones del templo de Delfos que pertenecen al siglo IV aC.

Un problema adicional es entender qué clase de documento es el catálogo. Se cree que es una lista para llamar a las ciudades a unirse a una guerra, o una lista de los participantes de una campaña militar, o una asamblea para la guerra. Una de las razones para creer esto es que el catálogo describe los contingentes usando el tiempo imperfecto, lo que significa que se refiere a un pasado remoto cuando se hizo la reunión de todos los guerreros en Áulide antes de zarpar a Troya. MorpurgoDavies (1960, p. 184) concluye que el catálogo y la Ilíada están compuestos independientemente el uno del otro, ya que el imperfecto denota que la acción se está desarrollando mientras que la Ilíada narra el noveno año de la guerra. El im- 
perfecto, que narra el número de naves, crea un anacronismo con la situación que pretende describir. Beye (1961, p. 370-378) considera que las expresiones "nees eponto" y "nees estichonto" es más apropiada para objetos animados y no para naves que han estado ancladas en Troya por nueve años. El imperfecto se usa para describir hechos históricos, es así que Chantraine explica que la Odisea usa el imperfecto o el presente indicativo para hacer descripciones geográficas. Esa aparente falta de relación entre el catálogo y la Ilíada llevó a Leaf (1915, p. 230-242) a considerar que "el infeliz catálogo" como él lo llama reduce la geografía griega al absurdo ya que presenta una concepción desatinada de la geografía histórica.

Una opinión relacionada con ésto es pensar que la geografía del catálogo está basada en una serie de rutas seguidas por oficiales para reclutar guerreros para una guerra diferente a la guerra de Troya. Esta opinión está preservada en la idea de que existió una lista de ciudades separada de una lista con el número de embarcaciones. Page considera que la lista de ciudades proviene de la época micénica mientras que el número de naves es una adición jónica. De hecho, el catálogo contiene elementos de lenguaje tardío de procedencia jónica del siglo VIII aC, Shipp (1953, p. 235-237) ha demostrado que el catálogo junto con los símiles es la parte de la Ilíada que contiene más elementos lingüísticos tardíos. Uno de estos elementos es la palabra "naves", la forma jónica es "nees" mientras que la forma micénica debe ser "nawes", según lo registrado en las tablillas del lineal B. En veinte ocasiones la palabra "nawes" aparece, mientras que en nueve ocasiones se usa la palabra "nees" seguida del verbo "estichonto" que es una formación secundaria que no es de origen micénico. Esto se ha usado como evidencia para argumentar que el número de las naves es una contribución jónica a una lista de ciudades de origen micénico.

Adicionalmente, la ausencia de referencias explicitas a los Dorios hace pensar que la geografía del catálogo es micénica. Hay omisiones de ciudades dorias importantes como Esparta y Mégara. Pero también existen omisiones de centros micénicos importantes como Gla y Dendra y esto hace pensar que la geografía del catálogo no es micénica. Existen problemas con la descripción del Peloponeso: con el reino de Agamenón y Diomedes y con la ubicación del palacio de Néstor. La argólide está divida entre los contingentes de Agamenón y Diomedes. Esto es problemático ya que el reino de Agamenón no posee acceso a la costa y él era quien poseía el mayor número de naves (100 barcos). Diomedes es rey de Argos, y su reino está superpuesto al de Agamenón. El reino de Agamenón está dividido en secciones y no es ni siquiera el rey de Argos, es decir no domina la planicie que le queda en frente. También es difícil de creer que Micenas y Argos separadas sólo 
por ocho millas sean dos reinos distintos. El hecho de que Agamenón sea el rey de todas las islas y de todo Argos (Il.2.108) es difícil de reconciliar con Diomedes como rey de Argos y Tirinto. Ese problema de superposición de reinos parece indicar que la descripción refleja el conocimiento de ese área de distintas épocas históricas.

La Ilíada pretende mostrar la superioridad de Micenas sobre las otras ciudades del Peloponeso, poniendo por debajo a Argos que fue su rival. Sin embargo, en Hesíodo existe una tradición geográfica diferente que privilegia a Argos sobre Micenas. En Hesíodo, Argos está gobernado por Ajax, y los lugares de la Argólide como Epidauro, Egina, Hermione, Asine y Corinto le pertenecen. Finkelberg (1988, p. 40) considera que esas dos tradiciones se unieron en algún momento del siglo $\mathrm{VI}$ aC, quitando a Ajax del espectro épico ya que éste, está representado con bajo perfil en la Ilíada y su reino ha sido dividido entre otros. En la Ilíada, Ajax es líder de Salamina lo que muestra el interés de que no pertenezca a la Argólide y el paradigma de la guerra de Troya remplaza con éxito el paradigma del ciclo Tebano.

Veamos los problemas del reino de Néstor. La zona arqueológica donde Pilos fue descubierta no corresponde con exactitud a la localización del reino de Pilos en la Ilíada. En las tabletas de lineal B descubiertas en Ano Englianos, el nombre pu-ro aparece frecuentemente, pero los límites del reino de Néstor en el catálogo no corresponden a los descubiertos en las tablillas. El Pilos homérico está situado en Mesenia, localizado 50 millas al sur de la desembocadura del río Alfeio, y también las ciudades al sur del cono del Peloponeso forman parte del reino de Pilos (Il.9.149-153), lo que dificulta aún más su correspondencia con las tablillas. No obstante, en la antigüedad Estrabón sitúa a Pilos en Trifilia, mucho más cerca del río (Estrabón VIII,359) y basa su opinión en el viaje que realizó Telémaco de Pilos a Itaca (Odisea 15. 296-300) y en las memorias de Néstor sobre la guerra contra los Epeos (Ilíada 11.670). Adicionalmente, es importante notar que las tablillas describen la zona mostrando áreas grandes en forma de distritos, mientras que el Pilos homérico, situado por el mito en Mesenia, está descrito por ciudades.

Omisión de lugares importantes, superposición de otros y ambigüedades sobre las fronteras de los reinos son los problemas más comunes que ocurren en el catálogo. Si nosotros consideramos que el catálogo es una fuente histórica para juzgar el conocimiento de Homero sobre Grecia, concluiríamos que su conocimiento del Peloponeso es pobre, y si no admitimos una perspectiva literaria tendríamos que decir que su intento en crear una unidad política creíble del Peloponeso no es exitoso. 
La composición oral intenta unificar diferentes tradiciones míticas privilegiando la tradición de la guerra de Troya. Griffin considera que el problema de la descripción de Homero del Peloponeso se debe a la superposición de los reinos de Néstor y Diomedes, que no pertenecen originalmente a la saga de Troya, sino a una anterior que luego fue unida a la Ilíada; Diomedes pertenece al ciclo Tebano, y Néstor era miembro de otra generación. Es así que la historia de la guerra de Troya actúa como un gran imán atrayendo y uniendo otras sagas. Gracias a la transmisión oral de la épica, cada historia era introducida en conexión con su localización original donde se desarrollaron los eventos, y cada historia proviene de un período histórico diferente en donde las fronteras y los reyes cambian. Esta debe entenderse como la causa de la confusión de la imagen homérica de la geografía del Peloponeso.

El catálogo contiene versos interpolados. Existen una disputa sobre si los versos sobre Atenas y Salamina son una adición tardía. En la primera mitad del siglo VI aC. Atenas y Mégara peliaban por la posesión de Salamina. La omisión de Mégara del catálogo hace pensar a algunos que Atenas fue introducida al catálogo en el siglo VI aC cuando Pisístrato instauró las Panateneas; de hecho los megarenses acusan a Pisístrato de incluir a Atenas en el Catálogo. Atenas no es una ciudad importante en la saga de Troya y además no es descrita con las mismas características de los otros contingentes del catálogo ya que estos están descritos mencionando varias ciudades del área, y no hay mención en el caso de Atenas de otros pueblos del Atica. Podemos considerar la presencia de Atenas en el catálogo como una forma de justificar su rol importante en los asuntos políticos. Esta interpolación es evidencia de la importancia que significaba para una ciudad ser mencionada en el catálogo y esto resalta la idea de que el catálogo es un mapa de Grecia y es clara la relación de poder que existe en su información geográfica.

Una anomalía atribuída al catálogo es su falta de relación con el resto de la Ilíada. Comúnmente se opina que el catálogo es un poema más temprano que luego fue modificado y unido al tema de la guerra de Troya. Algunos consideran posible que en algunas ocasiones la Ilíada se recitaba sin el catálogo. Sin embargo otros consideran que el catálogo forma parte original de la Ilíada y basan su opinión en los pasajes de Filoctetes (Il.2.721-725) y Protesilao (Il.2.695-702). En ambos pasajes el poeta sabe que estos héroes mueren antes de iniciar los combates y conocen sus reemplazos. El hecho de que el poeta conoce algo sobre el inicio de la guerra hace pensar que el catálogo es una canción antigua que trata sobre la asamblea de guerreros en Áulide. El problema con esta opinión es que realza la noción romántica de que el catálogo preserva la memoria de una guerra real panhelénica. West (1973, p. 192) considera que si la guerra de Troya se realizó, ésta debió haber 
sido una pequeña coalición entre dos bandos y que luego por transmisión oral se engrandeció y se volvió un asunto panhelénico.

El mito de Troya se relaciona principalmente con el área geográfica del Peloponeso. La Ilíada introduce otros mitos como la historia del jabalí de Calidonia que se desarrolla en Etolia. Sin embargo, existen otras tradiciones míticas importantes que están ausentes de la Ilíada como la destrucción de Tebas, y los mitos de Argos. Tampoco hay mitos sobre el norte de Grecia (Tesalia). El Peloponeso de Homero basa su geografía en los mitos, pero la geografía del norte de Grecia y de Beocia pertenecen a una geografía real que quizás data del siglo VIII aC ya que no se han encontrado en Tesalia palacios micénicos. El caso de Beocia es interesante, Beocia es el lugar del mito por excelencia, allí desarrolla su actividad poética Hesíodo, y la tragedia griega hace uso principalmente de la geografía de Beocia: el monte Helicón, el monte Citerón, el lago Copais, y Tebas. Sin embargo, la Beocia de Homero omite este conocimiento geográfico procedente de los mitos y se basa en la enumeración de ciudades insignificantes dejando de lado al mito y a una ciudad micénica muy importante que floreció en Beocia y que se llama Gla. Los Beocios son los primeros en ser nombrados en el catálogo, es el lugar descrito con más detalle y la descripción geográfica más larga y además es el contingente que posee mayor numero de guerreros. Sin embargo en la Ilíada los líderes Beocios no son importantes. El papel insignificante de los beocios en la Ilíada no es consistente con la descripción geográfica de su región. Beocia está descrita por centros urbanos, se mencionan todas las ciudades situadas al sur del lago Copais a manera de Periplo siguiendo el giro contrario de las manecillas del reloj, esta es la representación de la Beocia del siglo VIII aC. Contemporáneo con el poeta es también la ciudad de Corinto, que no posee remanentes micénicos y que fue en el siglo VIII $\mathrm{aC}$ un emporio comercial.

El catálogo muestra la superposición de épocas históricas y por lo tanto no puede considerarse como un mapa histórico y real de Grecia sino que debe ser estudiado como un mapa cultural de Grecia, y eso quiere decir, una concepción geográfica en donde quedan pasmados aspectos históricos contemporáneos al poeta junto con apectos mitológicos que dan sentido de pertenencia y de cultura a la noción de espacio. De esta forma el espacio abstracto se vuelve "lugar" y el relato geográfico se une a la idea de construir una unidad política y cultural, es decir se visualiza una "nación".

Volvamos a la idea sobre la repercusión de la literatura de viajes en la conformación del pensamiento geográfico. 


\section{El périploy los mapas}

El catálogo no es la descripción de un viaje, pero construye el espacio con base en historias de viajes, viajes que otros realizaron y a cuya información tuvo acceso el aedo gracias a la transmisión oral de la poesía. A pesar de que el catálogo no construye la geografía a manera de guía, es decir, un itinerario que pueda seguir seguido, sin embargo contiene indicios de que está basado en historias de Periplos. Existen dos teorías acerca de la fuente sobre la cual Homero pudo haber basado su información geográfica:

a) La geografía del catálogo se puede asociar con un origen religioso. Como mencioné al inicio de este artículo Giovannini (1969, p. 51-52) piensa que el catálogo está basado en las listas de los theorodokoi de Delfos.

b) El catálogo fue compuesto en Beocia bajo la influencia de la poesía de catálogo, un género que se cree fue cultivado particularmente en Beocia, ya que existen manifestaciones de ello en Hesíodo en su Catálogo de las mujeres y en sus antecedentes llamados ehoie.

Aunque no es posible establecer con certeza las fuentes del conocimiento geográfico expresado en Homero, sí es posible conocer las ideas geográficas que circulaban en la antigüedad y cómo éstas aparecen plasmadas en la geografía homérica. Las dos teorías expresadas arriba no pueden dar una explicación total para entender el catálogo; mi contribución radica en interpretar el catálogo a la luz de la literatura de viajes y explicar que la noción de Periplo subyace a la construcción geográfica del catalogo de las naves de la Ilíada.

El Periplo es la descripción de una ruta alrededor de la costa donde se mencionan las características más notorias del paisaje, las islas, las montañas, los ríos y las ciudades. Construye el espacio linealmente en una dimensión, en contraposición a la noción moderna del espacio visto desde una perspectiva aérea en dos dimensiones. Aún los dioses homéricos que pueden volar no describen el paisaje desde el aire sino una vez tocan tierra firme. Un ejemplo de Periplo es Ilíada 14. 225-230, 281-285 en donde se describe el viaje de Hera desde el Olimpo hasta Lemnos y finalmente a Troya. La diosa no cruza el Egeo por la ruta más corta sino que viaja alrededor bordeando la costa, va a Tesalia, Tracia y el Monte Atos, llegando a la isla de Lemnos. Desde allí va a la isla de Imbros y finalmente al Monte Ida. Esa es una ruta náutica seguida por los navegantes; debido a los fuertes vientos del mar Egeo, las embarcaciones no se aventuraban mar adentro sino que seguían la ruta de la costa. 
Los antiguos utilizaron el modelo del Periplo que da una visión lineal como a lo largo de un itinerario. Esta visión da pocas orientaciones veraces, y enumera una serie de rótulos geográficos en forma de lista. Es narrado en primera persona como aparece ejemplificado en la Odisea. La primera versión literaria del Periplo se cree que fue preparada para Darío I por Escílax de Carianda en el siglo 4aC. Algunos recuentos fueron marítimos y de exploración como el de Piteas en Gran Bretaña, y el de Hanón por el Atlántico siguiendo la costa de Marruecos. Otros fueron con fines militares o políticos como todos los recuentos que siguieron las conquistas de Alejandro Magno en Oriente y en India. Estos recuentos tienen mucho en común con la literatura fantástica. A pesar de que el catálogo menciona lugares al interior del continente y no solamente de la costa, el sentido de Periplo permanece, debido a que la descripción odológica, que es el nombre que recibe las descripciones del espacio en una dimensión tal como aparecen en el periplo, es la base de toda las descripciones geográficas de la antigüedad (Janni, 1984, p. 84). Es por esta razón que, aunque el catálogo no puede considerarse un Periplo en sentido estricto de la palabra, sí posee influencia de éste en cuanto comparte la organización del espacio en una sola dimensión.

Descripciones de viajes y guías de viajeros son testimoniadas en el Anábasis de Jenofonte y en la obra de Pausanias. Veamos ambos ejemplos. El Anábasis narra el viaje que hicieron mercenarios griegos al Asia y su regreso hacia el Mar Negro (Ponto Euxino) y describe ciudades y rótulos geográficos significativos.

Desde allí marchó tres estadios, veinte parasangas hacia Celene, ciudad frigia, grande y prospera. Allí Ciro tiene un palacio y un jardín paraíso lleno de animales salvajes, donde él caza montado a caballo, cada vez que quiere hacer ejercicio en un caballo. A través de este parque pasa el río Meandro, cuyas fuentes están debajo del palacio y fluye también a través de la ciudad de Celene" (Anabasis I.ii.7; traducción mía).

Pausanias tiene otra perspectiva cuando narra los lugares visitados, él se centra en la descripción de los monumentos religiosos y sus decoraciones:

En Patras, no lejos de los de Poseidón, están los santuarios de Afrodita. Cerca al puerto hay dos estatuas de bronce, una de Ares y otra de Poseidón. Una de las dos estatuas fue recogida por un pescador con su red una generación antes de mi tiempo. La estatua de Afrodita, cuyo santuario también está cerca del puerto, tiene la cara, las manos y los pies de piedra, y el resto de la figura está hecha en madera. 
También hay una gruta cerca al mar, por donde en el verano es muy agradable hacer caminatas y pasar el tiempo. En esta gruta hay dos templos, uno a Apolo y otro a Afrodita. Las estatuas de éstos dos están hechas en piedra. Cerca a la gruta está el santuario a Demeter, ella y su hija están de pie, pero la estatua de la diosa Gea es una imagen sentada. En las afueras del santuario hay una fuente..." (12.811; traducción mía).

La geografía siempre ha estado asociada a la concepción de mapa. Los mapas son construcciones sociales que han sido una herramienta central en los estudios etnográficos, son definidos como representaciones gráficas que facilitan la comprensión de conceptos, condiciones procesos y eventos de determinados grupos humanos (Harley and Woodward, 1987, v. 1, p. xv-xxi, esp. p. xvi).

En la Ilíada hay descripciones verbales de mapas, la repartición de la tierra entre los dioses es precisamente uno de los mapas que aparecen en la Ilíada:

Tres somos los hermanos nacidos de Crono a quienes Rea alumbró:

Zeus, yo y, el tercero, Hades, soberano de los de bajo tierra

En tres lotes está todo repartido, y cada uno obtuvo un honor:

A mí me correspondió habitar para siempre el canoso mar,

Agitadas las suertes; el tenebroso poniente tocó a Hades,

Y a Zeus le tocó el ancho cielo en el éter y en las nubes.

La tierra es aún común de los tres, así como el vasto Olímpo

(Ilíada 15.187-193; trad. Crespo).

Estos mapas verbales que se conocen como logos ilustrativo, son descripciones orales de mapas que debieron tener su correlativo pictórico pero que desafortunadamente no sobrevivieron para llegar a nosotros. Se sabe que los mapas fueron utilizados en Mesopotamia desde un período temprano y es posible que los mapas griegos tuvieran influencia oriental. De hecho la Ilíada posee mucha influencia oriental y este mapa de Ilíada 16 está basado en la concepción cosmológica mesopotámica (Burkert, 1981, p. 51-56). También puede considerarse el escudo de Aquiles como la descripción de un mapa.

Existen otros casos de mapas orales testimoniados en Heródoto y Aristófanes:

Aquí están los jonios y aquí están los lidios quienes habitan una tierra fértil y tienen una gran reserva de plata (mientras hablaba 
mostraba el mapa de la tierra que estaba grabado en una tabla) y los que están al lado de los lidios, los ves, son los frigios, al este, de entre los hombres que conozco los más ricos en ganado y en todo cuanto la tierra produce. Cerca a ellos están los capadocios, a quienes nosotros llamamos sirios, sus vecinos son los cilicios cuyo territorio llega hasta los confines con el mar, y aquí tu ves, yace la isla de Chipre (Heródoto 5.49; traducción mía);

- Mira esta es una carta (ges periodos) de todo el mundo, la ves?

Esta ciudad es Atenas

- Que dices? no te creo

no veo a los jueces allí sentados.

- En verdad te digo que ese es el suelo de Ática

...y aquí está Eubea.

- Y dónde está Esparta?

- Déjame ver, aquí.

- Muy cerca a nosotros. Por favor has esto, muévela lejos de nosotros, más allá.

(Aristófanes, Las nubes, 206ss; traducción mía)

La oikumene (la tierra habitada) era considerada una superficie plana y redonda rodeada por el río Océano ${ }^{2}$. Los griegos antiguos de la época arcaica y clásica no utilizaban la palabra geografía que se cree fue acuñada por Eratóstenes en el s. II aC. La palabra utilizada era ges periodos que denotaba una carta geográfica o su descripción verbal. La palabra pinax era utilizada para designar mapas (Romm, 1992, p. 26-31; Heidel, 1937, p. 11-24). Anaximandro ca. 550 aC. es acreditado de hacer el primer mapa, el prototipo de los mapas jónicos de los que Estrabón habla cinco siglos después, y los cuales Aristóteles criticó (Mete. 2.5 362b).

Heródoto se refiere a los mapas jónicos en el pasaje en que Aristágoras de Mileto le presenta a Cleómenes de Esparta un mapa de Asia con el fin de persuadirlo a una guerra (ver cita arriba), el mapa es la descripción verbal de lo que está grabado sobre una tabla (pinax). Existieron en Roma mapas conocidos como itineraria picta, un ejemplo de ello es la famosa Tabula Peutingeriana que es la descripción gráfica de un itinerario representado en forma lineal en una dimensión. A pesar de que no existen mapas gráficos de Grecia o que éstos no sobrevivieron, es posible sin embargo decir que la Ilíada contiene un gran mapa y que éste está descrito oralmente en el catálogo de las naves.

2 Sobre esta idea del río Océano, ver Romm (1992, cap. Xx). 


\section{El catálogo como mapa cultural de Grecia}

La geografía es una construcción cultural de la identidad griega donde conviven el pasado heroico y el presente del poeta (siglo VIII aC). El Catálogo representa la recolección de nombres y ciudades de los héroes que añoran su patria una vez en Troya y tiene el potencial de desarrollar historias de retorno (nostos) como el regreso de Odiseo a su patria narrado en la Odisea, en efecto Itaca está descrita en el catálogo de la misma forma como Odiseo la recuerda.

El catálogo puede ser visto como una máscara que encubre nombres y ciudades de otras sagas perdidas ahora para nosotros. El catálogo guarda la memoria de un pasado épico, donde los guerreros se enrolaron en numerosas y diferentes batallas a través de muchos siglos. El hecho de que la memoria se conserve en un texto de descripción de paisajes refleja la potencialidad del catálogo como documento de identidad.

El catálogo es un mapa cultural de Grecia, de hecho la investigación antropológica en sociedades orales dan ejemplos de performance de mapas recitados en eventos políticos o religiosos y en los cuales el conocimiento geográfico forma parte importante de la conformación de la cultura, del prestigio y del sentido de pertenencia a una localidad determinada. Por ejemplo, el lukasa, un tablero cubierto con cuentas y conchas marinas de la República Democrática del Congo es cantado para recordar los viajes del rey, la localización de los lagos sagrados, árboles, y rutas migratorias. El contenido cambia de acuerdo al rey que es venerado y según las circunstancias de la puesta en escena (Woodward y Davis, 1992, v. 2, p. 32-33). En Sur América también existen casos de mapas orales en algunas tribus indígenas. En ritos chamánicos de los grupos Tukano y Denasa del Amazonas, y Baranasa en Colombia se muestra un conocimiento geográfico oral que se pone en escena en ocasiones religiosas.

Adicionalmente, la importancia del conocimiento geográfico fue reconocido por Aristóteles, y existen testimonios de que los mapas fueron utilizados como un objetos didáctico en el salón de clases, tal y como aparece ejemplificado en Las Nubes de Aristófanes, arriba citado. En Roma los mapas eran colocados a la entrada de edificios públicos como en templos con el fin de engrandecer y dar prestigio al imperio con relación a su expansión y triunfos militares. Los mapas gráficos u orales son propagandas políticas y constituyen formas de pensar de una colectividad.

La Ilíada posee un gran mapa de Grecia, éste puede ser visto u oído en el catálogo de las naves. Está basado en las historias de viajes, y muestra un interés 
colectivo unido a un tema de guerra, con valores mitológicos que explican la pertenencia y el significado simbólico de determinados lugares para sus habitantes. Unido a una empresa militar, como es la guerra de Troya, crea un sentido de unidad nacional, en el cual los distintos contingentes aliados a Micenas conforman una unidad simbólica cultural.

Unir el tema de la identidad con la descripción del paisaje de la tierra patria es uno de los temas más desarrollado recientemente en los estudios culturales. Por ejemplo, Bhabba (1990) y Shama (1995) consideran que el estudio del paisaje es uno de los factores más importantes en la construcción de nación y de pertenencia. El relato de Chadwin songlines, narra la relación entre geografía y canción para los aborígenes australianos:

- (Aborigen) Una canción era al mismo tiempo un mapa y una dirección. Si usted conoce la canción siempre puede encontrar su camino en este país.

- (Autor)Y un viajero errante siempre debe viajar por los caminos trazados por las canciones?

- (Aborigen) En el pasado sí, ahora se viaja en tren y en carro.

- (Autor) Entonces la canción es una especie de pasaporte o de tiquete para comprar comida?

- (Aborigen) es más complicado que eso. En teoría toda Australia puede ser leída en forma de canciones. No hay roca o pico de este país que no haya sido cantado. Quizás uno debe visualizar las rutas de canciones como un spaghetti de Ilíadas y Odiseas, que se retuerce por aquí y por allá, en el cual cada episodio podía ser leído en términos de Geología.

(Songlines "rutas de canciones").

A pesar de que la geografía griega antigua tiene tres directrices principales: documentación corta de rutas particulares como por ejemplo la Perigesis de Hecateo de Mileto, ideas y descripciones sobre la oikumene como las historias de Heródoto que combinan geografía y etnográfica, y la geografía matemática, ejemplificada por Eratóstenes y Tolomeo, es posible añadir un cuarto aspecto fundamental de la geografía antigua que es su característica de ser geografía humana, siendo ejemplo de ello Homero, Heródoto, Jenofonte, Pausanias y Estrabón.

El pasaje citado de Chatwin muestra la importancia de que la geografía debe estar unida al sentido de pertenencia de una determinada localidad. De he- 
cho, la geografía humana tal como aparece representada en Homero tuvo gran influencia en el desarrollo posterior de la geografía como ciencia. Para Estrabón por ejemplo, su visión del mundo incluye al mito como parte fundamental del conocimiento geográfico. El mito asociado a ciertas localidades era una forma de entender el espacio y de ligarse a éste por medio de historias que daban sentido de pertenencia a una colectividad determinada. Además, según Estrabón, el mito dentro del pensamiento geográfico era una herramienta didáctica para enseñar geografía.

El catálogo es un texto de descripción del paisaje Griego unido al tema de la patria; por lo tanto conforma un mapa cultural de Grecia. Este, gracias a la tradición oral, pudo ser modificado y transformado a lo largo de los siglos, pudiendo ser utilizado como un mapa vigente en diferentes períodos de la historia griega. Allí quedaron plasmados aspectos geográficos reales e históricos ligados con informaciones mitológicas e historias épicas que dieron sentido de pertenencia y unidad cultural al pueblo griego.

\section{REFERÊNCIAS BibLIOgRÁficas}

Allen, T. W. The Homeric Catalogue of Ships. Oxford: 1921.

Anderson, J. K. The Geometric Catalogue of Ships. In: Carter, J. B.; Morris, S. P. (ed.). The Ages of Homer. Austin: 1995.

Antonaccio, C. Lefkandi and Homer. In: Anderson, O.; Dickie, M. (ed.). Homer's World: Fiction, Tradition Reality. Bergen: 1995.

Baladié, R. Le Peloponnèse de Strabon. Paris: 1980.

BÉRARD, V. Les Navigations d'Ulysse. Paris: 1927-1929. v. I.

BeyE, C. R. "A New Meaning for naàj in the Late Catalogue". American Journal Philology. n. 82, p. 370-378, 1961.

BHABBA, H. Nation and narration. Londres: 1990.

Bocchetti, C. El espejo de las musas: el arte de la descripción en la Ilíada y Odisea. Centro de Estudios Griegos, Bizantinos y Neohelénicos "Fotios Malleros", Universidad de Chile, 2006.

. "The periplous tradition in the Iliad and the Homeric Hymns". ARGOS, Revista annual de la asociación Argentina de Estudios Clásicos. v. 29, p. 29-52, 2007. 
. "El Catálogo de las Naves y los Himnos Homéricos". NOVA TELLUS: Anuario del Centro de Estudios Clásicos. Instituto de Investigaciones Filológicas, Universidad Autónoma de México, v. 24.2, p. 41-75, 2006.

- "Hacia una nueva lectura de la geografía en la Ilíada". Revista Synthesis. Universidad Nacional de La Plata, v. 12, p. 79-98, 2005.

. "Cultural geography in Homer". ERAS Journal. School of Historical Studies of Monash University in Australia, online Journal, 5th edition, p. 1-30, 2003. Bowra, C. M. Tradition and desing in the Iliad. Oxford: 1930. . "Homeric Epithet for Troy". Journal of Hellenic Studies. n. 80, p. 16-23, 1960.

Burkert, W. Oriental Myth and Literature in the Iliad. In: HäGG, R. (ed.). The Greek Renaissance of the Eighth Century B.C.. Estocolmo: 1981.

. Greek Religion. Cambridge Mass.: 1985.

Buxton, R. "Imaginary Greek Mountains". Journal Hellenic Studies. n. 112, p. 1-15, 1992. . Imaginary Greece: the contexts of mythology. Cambridge: 1994.

CAmps, W. A. An Introduction to Homer. Oxford: 1980.

Cary, M.; Warmigton, E. H. The Ancient Explorers. Londres: 1929.

CHADwick, J. The Mycenaean World. Cambridge: 1973.

Chantraine, P. Dictionnaire étimologique de la langue grecque. Paris: 1953. v. II.

Clarke, C. Between Geography and History. Oxford: 1999.

Cordano, F. La Geografia degli Antichi. Roma / Bari: 1993.

Cosgrove, D.; Daniels, S. The Iconography of Landscape: essays on the symbolic representation design and use of past environments. Cambridge: 1988.

Crossett, J. "The art of Homer's Catalogue of Ships". Classical Journal. v. 64, p. 241-245, 1968.

Davinson, J. A. "Peisistratus and Homer". Transaction American Philological Association. v. 86, p. 1-21, 1955.

Dickie, M. The geography of Homer's world. In: Andersen, O.; Dickie, M. (ed.). Homer's World, Fiction, tradition, reality. Bergen: 1995.

Dilke, O. A. W. Greek and Roman maps. Ithaca: 1985.

Dion, R. Aspects politiques de la géographie antique. Paris: 1977.

Finkelberg, M. "Ajax's entry in the Hesiodic Catalogue of Women". Classical Quartely. v. 38: p. 31-41, 1988. 
Germain, G. Genèse de l'Odyssée. Paris: 1954.

Giovannini, A. Étude historique sur les origines du Catalogue des Vaissaux. Berne: 1969.

GrifFIN, J. "Homeric Pathos and Objectivity". Classical Quartely. v. 26, p. 161-187, 1976. . Homer on Life and Death. Oxford: 1980.

. "Homeric Words and Speakers". Journal Hellenic Studies. v. CVI, p. 36-56, 1986.

. "Homer Pastoral and the near East". Studi Italiana di Filologia Classica. v. 10, p. 553-576, 1992.

. Homer: Iliad Book Nine. Oxford: 1995.

Hardie, P. R. "Imago mundi: Cosmological and ideological aspects of the shield of Achilles". Journal Hellenic Studies. v. 105, p. 11-31, 1985.

Harley, B.; Woodward, D. History of Cartography. Chicago: 1987. v. I.

Heidel, W. A. The Frame of the Ancient Maps. New York: 1937.

Hope Simpson, R.; Lazenby, J. F. “The Kigdom of Peleus and Achilles”. Antiquity. v. 33, p. 102-105, 1959.

. The Catalogue of the Ships in Homer's IIiad. Oxford: 1970.

Janni, P. La Mappa e il Periplo: cartografia antica e spazio odologic. Roma: 1984.

Le Termopili: geografia e historia. In: Prontera, F. (ed.). Geografia storica della Grecia antica. Roma / Bari: 1991.

KIRK, G. S. The Songs of Homer. Cambridge: 1962.

. Homer and the epic. Cambridge: 1965.

. Homer and the Homer tradition. Cambridge 1976.

. The Iliad: a commentary. Cambrigde: 1985. v. I.

LEAF, W. Troy: a Study in Homeric Geography. Londres: 1912.

. Homer and History. Londres: 1915.

. Strabo on the Troad. Cambridge: 1923.

LORD, A. B. The Singer of Tales. Cambrigde Mass: 1960.

Malkin, I. The Returns of Odysseus. Berkely / L.A.: 1998.

Millard, A. R. Cartography in the Ancient Near East. In: Harley, J. B.; WoOdwARd, D. (ed.). History of Cartography. Chicago / Londres: 1987. v. I. 
Morpurgo-Davies, A. Recensioni a D. Page. History and the Homeric Iliad. Rivista di Filologia. v. 38: p. 178-191, 1960.

Page, D. History and the Homeric Iliad. Berkeley: 1959.

. Review to Jachmann, 1958. Classical Review. v. 74, p. 105.

PÁramo, J. "El loto de Odisea". Texto y Contexto. Universidad de Los Andes, Bogotá, 1991.

. Sorteo, lotes y herencia en Grecia Antigua: a propósito de Ilíada XV 187-

193. Micenas y Homero. Instituto Caro y Cuervo, Bogotá, 1995.

Parry, M. The making of Homeric verse. In: PARrY, A. (ed.). The Collected Papers of Milmam Parry. Oxford: 1987.

Romm, J. The Edges of the Earth in Ancient Thought. Princeton / New Jersey: 1992.

Schama, S. Landscape and Memory. Londres: 1995.

SHIPP, G. P. Studies in the Language of Homer. Amsterdam: 1953.

Van PaAssen, C. The Classical Tradition of Geography. Groningen: 1957.

Vernant, J.-P. Mythe et Pensee chez les Grecs. Paris: 1965.

. "Hestia-Hermes: the Religious Expression of Space and Movement in Ancient Greece”. In: . Myth and thought among the Greeks. Londres: 1983.

Vidal-Naguet, P. "Land and sacrifice in the Odyssey: a study of religious and mythical meanings". In: ScheIN, S. L. Reading the Odyssey. Princeton / New Jersey: 1996.

Visser, E. Homers Katalog der Schiffe. Leipzig: Teubner, 1997.

West, M. “Greek Poetry 2000-700 B.C.”. Classical Quartely. v. 33, p. 179-192, 1973. . Hesiod. Works and Days. Oxford: 1978.

. "The date of the Iliad". Museum Helveticum. v. 52, p. 203-219, 1995.

. The East side of Helicon. Oxford: 1997.

WOODWARD, D.; LEWIS, G. "Introduction". In: . The History of cartography.

Chicago: 1992. v. II, 1. 3.

BOCCHETTI, C. Homeric geography.

ABSTRACT: This paper studies the Catalogue of Ship in the Iliad as an oral map of Greece. It argues that the Catalogue serves as a cultural 
document which gives ideas of belonging and unity to the Greeks, and can be seen as an early example of panhellenism.

KEYWORDS: Homer; Catalogue of Ships; ancient geography; travel literature; oral maps. 